\title{
PEMANFAATAN SUMBERDAYA HUTAN DI HUTAN LINDUNG KECAMATAN ALU KABUPATEN POLMAN PROPINSI SULAWESI BARAT
}

\author{
The Utilization of Forest Resources in Alu Village Protected Forest, Polewali Mandar Distrinc, \\ Province of West Sulawesi \\ Asrianny $^{1 凹}$, Muhammad Dassir ${ }^{2}$ dan $^{\text {Asrianty }}{ }^{3}$ \\ ${ }^{1}$ Lab. Konservasi Sumber Daya Hutan dan Ekowisata, Fakultas Kehutanan Universitas Hasanuddin \\ ${ }^{2}$ Lab. Pemanenan Hasil Hutan, Fakultas Kehutanan Universitas Hasanuddin \\ ${ }^{3}$ Alumni Fakultas Kehutanan Universitas Hasanuddin, \\ Jl. Perintis Kemerdekaan Km. 10 Tamalanrea, Makassar 90245
}

\begin{abstract}
This study aims to determine the activity of the utilization of forest resources and to know local community wisdom related to protection forest in the Alu Village areas. This research was conducted by using Rapid Rural Appraisal (RRA) method. Respondents in this study were communities living in and around the protection forest area and conducting activities in the forms of utilizing the forest resources. The observed variables were the forms of community activities in the protection forest and local community wisdom in using the forest resources. The results show that activities of villagers consist of: 1) the use of timber for home construction or repair and for fuel wood, 2) the utilization of rattan, 3) the utilization of bamboo, 4) the utilization of palm, 5) the utilization of honey bee and other forest products. In addition, local community wisdom in the utilization of forest products was found to be in the form of prevailing institutions in the village of Alu. The forms of institutions are forest harvesting institutions, forest land use institutions, and forest protection and security institutions. In general, Alu Villagers have the awareness to preserve the environment, ecological balance and sustainability of the population to be bequeathed to their generation. Yet, the wisdom is prone to turn down particularly in the institution of timber utilization.
\end{abstract}

Key words: Forest resource utilization, protected forest, local wisdom, Alu Villagers

\section{PENDAHULUAN}

Pemanfaatan hasil hutan oleh masyarakat sekitar hutan perlu menjadi bahan pertimbangan bagi pemerintahan pusat dan daerah dalam membuat kebijakan berkaitan dengan kehutanan. Konflik kehutanan yang sering terjadi belakangan ini disebabkan oleh karena pemerintah tidak mengikutsertakan atau tidak mengaitkan peran serta masyarakat sekitar hutan dalam pengelolaan hutan. Masyarakat sekitar hutan adalah sekelompok orang yang masih memiliki dan mempertahankan peri kehidupan tradisional dari leluhurnya yang tinggal di daerah hutan yang di dalamnya masih terdapat

Diterima: 8 Juni 2012; Disetujui: 28 Agustus 2012

$\triangle$ Penulis korespondensi (corresponding author): jrmatangaran@yahoo.com keanekaragaman biologi yang khas (Iskandar, 1992).

Pemanfaatan hasil hutan sebagai sumber penghidupan bagi masyarakat Desa Alu sudah dilakukan semenjak dulu. Ketergantungan masyarakat Desa Alu terhadap hutan sangat besar. Mereka hidup dari hasil mengumpulkan hasil hutan seperti kayu bakar, madu, aren, bambu, rotan, membuka kebun coklat, kelapa dan kemiri di dalam hutan, menanam pisang dan ubi, memanfaatkan tanaman obat-obatan, mengambil pakan untuk ternak mereka serta memanfaatkan sumber daya air untuk kebutuhan sehari-hari.

Untuk memahami sejauh mana aktivitas dan kearifan lokal masyarakat Desa Alu yang ada di sekitar Kawasan Hutan Lindung Desa Alu akan hasil hutan, dipandang perlu untuk melakukan penelitian ini. Penelitian ini ditujukan untuk mengetahui aktivitas masyarakat Desa Alu pada 
Kawasan Hutan Lindung Kecamatan Alu Kabupaten Polman Propinsi Sulawesi Barat, serta kearifan lokal masyarakat dalam pemanfaatan sumberdaya hutan pada Kawasan Hutan Lindung.

\section{METODE PENELITIAN}

Penelitian ini dilaksanakan pada bulan Agustus sampai dengan bulan September 2010 di Kawasan Hutan Lindung Desa Alu Kecamatan Alu Kabupaten Polewali Mandar Propinsi Sulawesi Barat. Populasi dari penelitian ini adalah masyarakat di sekitar Kawasan Hutan Lindung tersebut.

Metode yang digunakan dalam pengambilan data menggunakan Metode Rapid Rural Apraisal (RRA), meliputi pengumpulan data primer dan data sekunder. Analisa data yang digunakan dalam penelitian ini adalah analisis deskriptif kualitatif. Analisis deskripsi kualitatif ini akan mendeskripsikan tingkat aktivitas masyarakat di dalam pemanfaatan kawasan hutan lindung. Data yang telah dikumpulkan kemudian dianalisis secara deskriptif kualitatif dengan unit analisis yang didasarkan pada data primer dan data sekunder. Hasil analisis kemudian ditabulasikan dan diklasifikasikan sesuai dengan tujuan penelitian.

\section{HASIL DAN PEMBAHASAN}

\section{Sejarah Kepemilikan Lahan di Desa Alu}

Berdasarkan informasi yang diperoleh dari tokoh-tokoh masyarakat Desa Alu diketahui bahwa sejarah kepemilikan lahan di dalam kawasan hutan lindung maupun di luar kawasan hutan lindung Desa Alu bermula dari budaya masyarakat dalam pengelolaan hutan yang ditunjukkan melalui model penguasaan lahan yang diwariskan secara turun temurun dari orang tua dengan istilah 'lita' sossorang". Penguasaan lahan tersebut tidak bisa dipindahtangankan dan tidak bertentangan dengan penguasaan negara terhadap kawasan hutan lindung. Saat ini masyarakat menyadari bahwa lahan yang mereka kuasai merupakan lahan negara dengan status kawasan hutan lindung. Penguasaan atas lahan tersebut mereka manfaatkan untuk pemungutan hasil hutan berupa pemungutan rotan, pemanfaatan aren dan bambu, pengolahan madu, gula merah, minyak goreng dan kopra serta pemungutan kayu bakar dan pemanfaatan kayu sebagai bahan untuk membuat dan memperbaiki rumah, sedangkan kegiatan pemanfaatan lahan dilakukan dalam bentuk aktifitas berkebun dan bertani.

\section{Karakteristik Kawasan Hutan Lindung Desa Alu dan Komposisi Jenis Penggunaan Lahan}

Karakteristik hutan di Desa Alu terdiri atas komposisi jenis tumbuhan serta pemanfaatan di dalam kawasan hutan lindung. Pemanfaatan lahan di kawasan hutan lindung sebagian besar digunakan untuk berkebun dan berladang yang di dalamnya ditumbuhi coklat (Theobrama cacao), mangga (Mangifera indica), ubi kayu (Manihot utilísima), pisang (Musa sp), kelapa (Cocos nucifera), kemiri (Aleurites moluccana), jambu mete (Anacardium occidentale), kopi (Coffeea sp), jambu biji (Psiduim guajava), jambu air (Zyzigium aquatica), nangka (Arthocarpus heterophylla) dan sayuran seperti lombok (Capsicum annum) sedangkan penutupan lahan di hutan alam terdiri atas tumbuhan seperti jenis paku-pakuan (Pteridophyta), bambu (Bambusa sp), bitti (Vitex cofassus), rotan (Calamus sp), aren (Arenga pinnata), beberapa jenis anggrek (Orchidaceae) dan masih banyak lagi tanaman lainnya. Pada hutan sekunder terdiri atas tanaman seperti jati (Tectona grandis), gmelina (Gmelina arbórea), gamal (Glicidia sepium), mahoni (Swietenia macrophylla), rotan, bitti, aren dan masih banyak lagi tanaman lainnya, sedangkan untuk semak belukar terdiri atas padang rumput, bambu, paku-pakuan, aren, jenis tanaman holtikultura seperti mangga, nangka, pisang dan jambu serta banyak lagi jenis tanaman lainnya.

Jenis-jenis tumbuhan alami antara lain pakupakuan, bambu, aren, rotan dan jenis-jenis tanaman hutan lainnya sedangkan tanaman hasil budidaya yang dijumpai di kawasan hutan lindung seperti coklat, kelapa, kemiri, pisang, gmelina, mahoni, kopi, sengon dan tanaman yang paling banyak dan sering dijumpai yaitu tanaman bambu, coklat, kelapa, aren, ubi dan pisang.

\section{Aktivitas Masyarakat Desa Alu pada Kawasan Hutan Lindung}

Bagi masyarakat Alu, hutan tidak hanya dipandang sebagai sekumpulan pepohonan dan tumbuh-tumbuhan lainnya yang tumbuh dalam suatu kawasan, melainkan mengandung nilai yang sangat kompleks. Ketergantungan masyarakat Alu terhadap hasil hutan sangat tinggi. Hal ini dapat dilihat dari sebagian besar masyarakat Desa Alu 
Tabel 1. Aktivitas masyarakat Desa Alu di kawasan hutan lindung

\begin{tabular}{rlll}
\hline No. & Aktivitas & Lokasi & Pemanfaatan Hasil Hutan \\
\hline 1. & Pemanfaatan Bambu & $\begin{array}{l}\text { Hutan Alam, Semak belukar, Pinggir sungai, } \\
\text { Kebun dan Ladang, Pemukiman, Hutan Sekunder, } \\
\text { Pagar Kebun dan Ladang }\end{array}$ & Bambu, Rebung \\
2. & $\begin{array}{l}\text { Pemanfaatan dan pemungutan } \\
\text { Kayu }\end{array}$ & $\begin{array}{l}\text { Hutan Alam, Hutan Sekunder, Semak Belukar, } \\
\text { Kebun dan Ladang }\end{array}$ & Kayu bakar, Kayu bangunan \\
3. & Pemanfaatan Aren & Hutan Alam, Hutan Sekunder, Jalan antar dusun \\
4. & Pemanfaatan Madu & Hutan Alam, Hutan Sekunder, Kebun dan Ladang & Nira, Batang \\
5. & Pemanfaatan Rotan & Hutan Alam & Rotan \\
\hline
\end{tabular}

yang mengandalkan pendapatan mereka dari berkebun di dalam dan di luar kawasan hutan lindung, mengumpulkan hasil hutan kayu, hasil hutan bukan kayu seperti madu, aren, rotan, bambu, dan berbagai jenis buah-buahan serta mengambil pakan untuk ternak mereka. Aktivitas masyarakat Desa Alu pada kawasan hutan lindung dapat dilihat pada Tabel 1.

Pemanfaataan lahan hutan dilakukan oleh masyarakat di luar dan di dalam kawasan hutan lindung. Jenis pemanfaatan lahan hutan yang dilakukan oleh masyarakat yaitu berkebun dan lahan ternak. Selain membudidayakan tanaman kayu-kayuan untuk menjaga kelestarian alam dan keberlangsungan ekosistem, lahan juga dimanfaatkan sebagai kebun yang ditanami dengan tanaman-tanaman yang bernilai ekonomi tinggi seperti cokelat dan kelapa. Masyarakat juga menanam pisang dan lombok untuk dikonsumsi sendiri/keluarga dan juga menjualnya ke pasar yang letaknya cukup jauh dari ibukota kecamatan. Pengelolaan tanah yang dilakukan oleh masyarakat di kebun adalah membuat teras atau bedenganbedengan untuk membatasi kebun-kebunnya. Masyarakat biasanya menggunakan pal-pal batas dari tumbuhan tanaman berkayu dan bambu. Selain beberapa jenis tanaman, lahan hutan juga dimanfaatkan oleh masyarakat sebagai tempat penggembalaan ternak (kuda dan sapi).

\section{Pemanfaatan Bambu}

Bambu merupakan salah satu hasil hutan bukan kayu yang sangat banyak ditemukan di Desa Alu. Jenis bambu tersebut tumbuh dan berkembang biak dengan sendirinya baik di dalam maupun di luar kebun dan ladang masyarakat yang berada di luar serta di dalam kawasan hutan lindung Desa Alu. Jenis tanaman ini dapat tumbuh di daerah pegunungan, lembah dan paling banyak tumbuh di sekitar sungai. Bambu juga banyak tumbuh di semak belukar, pemukiman warga dan di ladang atau kebun karena sering juga dijadikan pagar kebun, baik berupa pagar mati maupun pagar hidup.

Bambu banyak fungsi di antaranya untuk membuat dapur (paceko), tempat untuk menjemur pakaian, pagar, bahan pengikat, pipa irigasi, koker/ pot tanaman, alas untuk menjemur coklat dan pemenuhan kebutuhan bahan rumah tangga lainnya. Bambu juga banyak digunakan pada upacara adat pernikahan dan kematian. Masih ada pula masyarakat yang menggunakannya sebagai bahan untuk membuat dinding rumah. Pemanfaatan bambu sebagai salah satu hasil hutan bukan kayu oleh masyarakat Desa Alu belum banyak berubah. $\mathrm{Hal}$ ini terkait dengan pengetahuan dan teknologi yang dimiliki oleh masyarakat yang masih sangat minim.

Masyarakat Desa Alu pada umumnya mengambil bambu hanya untuk memenuhi kebutuhan sendiri dan belum merupakan sumber pendapatan bagi masyarakat setempat. Meskipun aktivitas pemanfaatan bambu masih tergolong rendah, namun keberlangsungan fungsi tanaman bambu mengalami degradasi yang cukup memprihatinkan karena selain dimanfaatkan sebagai bahan baku

alat-alat rumah tangga, masyarakat juga menebang bambu muda sebagai bahan sayuran (rebung), baik untuk dikonsumsi sendiri, maupun untuk dijual di pasar. Rebung yang dipanen di sini adalah rebung yang mempunyai tekstur agak lunak. Teknik pemotongan rebung yaitu memotong bagian bawah yang agak mengeras. Bagian yang terlalu keras memiliki rasa agak pahit. Bagian rebung yang dikonsumsi adalah bagian dalam yang berwarna keputihan, bagian ini lunak dan memiliki rasa yang enak. 


\section{Pemanfaatan Hasil Hutan Kayu}

Pemanfaatan kayu juga merupakan salah satu aktivitas yang dilakukan masyarakat Desa Alu pada kawasan hutan. Kayu digunakan untuk membuat atau memperbaiki rumah, membuat perabot rumah tangga dan kayu bakar. Pemilihan berbagai jenis kayu bergantung pada kebutuhan mereka. Untuk membuat rumah dan perabot rumah tangga, masyarakat Desa Alu memilih jenis kayu yang kuat seperti kayu jati, gmelina, bitti dan mahoni. Sedangkan kayu bakar mereka ambil dari ayu ranni (dahan dari berbagai jenis kayu yang berukuran kecil) dan beberapa jenis kayu yang cepat kering antara lain ayu bonga (gamal), ayu jolengjoleng (jambu), ayu ku'mil (nangka), ayu anging dan tippulu (Arthocarpus tejmanii).

Kayu bakar digunakan untuk perapian dan alat penerang pada malam harinya. Selain itu, kayu bakar kadang juga digunakan untuk perapian hewan peliharaan mereka seperti sapi, kambing dan kuda agar terhindar dari serangan serangga ataupun udara dingin pada malam hari atau disaat cuaca lagi dingin. Kayu bakar digunakan pula dalam industri kecil masyarakat Desa Alu untuk membuat dan memasak gula merah dan minyak kelapa serta digunakan pula untuk pembuatan kopra.

Pengambilan hasil hutan kayu digunakan untuk keperluan mereka sehari-hari dan tidak untuk dipasarkan. Kayu bakar biasanya diperoleh dengan beberapa cara yaitu memotong bagian-bagian tertentu dari pohon seperti ranting atau cabang, mengambil ranting-ranting pohon pada saat ada penebangan, untuk batang pohon yang masih basah dipotong lalu dibelah menjadi beberapa bagian lalu dikeringkan agar mudah menyala. Mereka mengumpulkan kayu dalam jumlah yang cukup banyak di musim kemarau untuk persediaan di musim penghujan.

\section{Pemanfaatan Aren}

Aren termasuk ke dalam jenis tanaman yang cenderung untuk berkembang biak dengan sendirinya karena mempunyai biji yang sangat banyak. Menurut masyarakatAlu tanaman aren yang mereka miliki sudah ada sejak dahulu dan mereka tidak pernah menanam aren karena tumbuh dengan sendirinya. Tidak banyak yang bisa dilakukan masyarakat Desa Alu untuk keberlangsungan tanaman ini karena menurut mereka biji tanaman aren agak susah dikecambahkan dan juga memerlukan waktu yang sangat lama. Kesulitan perkecambahan biji ini menjadi penyebab utama keengganan masyarakat membudidayakan aren secara besar-besaran, sehingga orang-orang lebih menyerahkannya pada perkecambahan alam. Sayangnya, pada saat mencabut bibit yang tumbuh secara alami ini, kemudian ditanam di lahan, banyak tanaman yang akhirnya mati sehingga masyarakat hanya membiarkan saja tanaman ini tumbuh secara alami.

Masyarakat Desa Alu sangat menjaga dan memelihara tanaman aren ini, anakan tanaman aren akan dipelihara dengan cara dipagari agar terhindar dari segala macam gangguan khususnya dari gangguan binatang seperti babi hutan. Aren banyak tumbuh di dalam hutan alam dan kebun karena tanaman aren mempunyai sifat dapat hidup berdampingan dengan jenis tanaman lain. Kegiatan mengambil aren oleh masyarakat Desa Alu tergolong sebagai kegiatan sampingan diselasela aktivitas berkebun. Karena itu aktivitas ini tidak menjadi kegiatan pencaharian pokok untuk ekonomi keluarga. Cara pemanenannya pun masih sangat tradisional sebagaimana yang secara turun temurun telah dilakukan. Aren selain dikelola menjadi gula merah untuk konsumsi sendiri dan untuk dijual, juga dikelola menjadii minuman tradisional yang dikenal dengan sebutan mayang atau tuak. Selain nira, batang aren pun sangat berguna untuk pembuatan jembatan untuk sungai-sungai kecil di desa, juga untuk pembuatan alat-alat penenunan kain tradisional Lita' Mandar (Tanah Mandar).

\section{Pemanfaatan Madu}

Kegiatan mengumpulkan lebah madu oleh masyarakat Desa Alu tergolong sebagai kegiatan yang dilakukan pada masa-masa senggang setelah berkebun. Karena itu pula, aktivitas ini tidak menjadi kegiatan pencaharian pokok untuk ekonomi keluarga. Cara pengambilannya pun masih sangat tradisional, sebagaimana yang secara turun temurun telah dilakukan. Cara pengambilan madu tersebut yaitu dengan cara mengasapi supaya lebah tidak mati dan ketika lebah sudah terbang maka petani akan mengambil madu dengan cepat sebelum lebah kembali ke pohon tersebut, cara ini dipercaya dapat menjaga ketersediaan madu dan keberlangsungan fungsi. 


\section{Pemanfaatan Rotan}

Rotan banyak tumbuh di dalam kawasan hutan lindung dan tanaman ini merupakan salah satu jenis hasil hutan bukan kayu yang banyak dipanen dari hutan, walaupun hanya beberapa orang saja yang melakukan pekerjaan ini. Hal ini karena jarak hutan yang ditumbuhi rotan terbilang cukup jauh, sehingga beberapa masyarakat memilih untuk berkebun coklat dan kelapa dan menjual rotan mereka ke pappajak. Pappajak adalah pedagang pengumpul rotan sekaligus yang memanen rotan tersebut karena mereka mempunyai kendaraan dan peralatan yang memadai untuk mengangkut rotan tersebut.

Pengelolaan rotan oleh masyarakat masih mengandalkan persediaan rotan alami. Sedangkan budidaya rotan belum dikenal sama sekali oleh masyarakat. Karena itu ketersediaan rotan alam merupakan jaminan bagi eksistensi aktivitas ini. Satu-satunya pranata yang ada tentang rotan adalah dilarang menebang rotan yang masih berumur muda dan di bawah panjang 4 meter serta meninggalkan beberapa rotan dalam satu rumpun pada saat pengambilan. Masyarakat pun tidak pernah tertarik untuk menanam rotan karena lebih tertarik untuk berkebun. Hal ini tentu saja mengancam eksistensi tanaman rotan ini dikawasan hutan lindung Desa Alu.

Kegiatan memanen rotan tidak mengenal musim kecuali pada saat intensitas hujan yang tinggi karena akan menyulitkan dalam melakukan kegiatan pengangkutan karena jalan yang tidak memungkinkan. Kegiatan memanen rotan dilakukan pada kawasan hutan belantara yang sangat jauh dan memakan waktu yang lama serta secara berpindah-pindah dan hal ini menyebabkan banyak masyarakat yang tidak tertarik merotan.

\section{Bentuk-Bentuk Kearifan Lokal Masyarakat}

Ketergantungan hidup pada alam melahirkan pengetahuan untuk hidup selaras dengan alam. Pengetahuan untuk hidup selaras dengan alam tersebutkemudian digunakan oleh masyarakatuntuk berinteraksi dengan lingkungan dimana mereka tinggal dan menetap. Menurut Radjam (2004) dalam Nurhayati (2005), kearifan lokal secara sederhana dapat diartikan sebagai sekumpulan tata nilai yang dipegang dan dijalankan masyarakat tradisional dengan mengacu pada nilai-nilai hubungan timbal balik antara manusia dengan lingkungan hidup, budaya setempat dan nilai-nilai yang berlaku di suatu masyarakat yang dapat ditemui pada pola bercocok tanam, tata ruang kampung, cerita rakyat bahkan permainan rakyat. Sedangkan Njurumana \& Gerson (2006) mengemukakan bahwa kearifan lokal dalam pemanfaatan hutan, tanah dan air memiliki ciri yang berbeda pada setiap komunitas masyarakat yang merupakan bagian integral dari aspek budaya dan religius masyarakat lokal sehingga banyak kearifan lokal memiliki nilai-nilai konservasi karena dibangun atas dasar kesadaran menyelaraskan kehidupan dengan alam.

Pranata-pranata sosial masyarakat di Desa Alu dalam memanfaatkan sumber daya alam mengindikasikan adanya kearifan lingkungan dan kearifan dalam pelestarian fungsi hidrologi hutan (konservasi air) dan pelestarian ekologi. Kearifan tersebut berupa larangan-larangan dan ajakan sepertilaranganmemanfaatkanlahan danmenebang pohon dalam kawasan pangngale piparakkeang. Ajakan untuk senantiasa menjaga kelestarian hutan untuk keberlangsungan ekosistem, menanam sebelum menebang agar fungsi hutan dapat terus dirasakan oleh anak cucunya kelak dalam hal ini kontinuitas fungsi hutan (konsevasi tanah).

\section{Kearifan lokal dalam bentuk larangan}

Sesuai dengan adat dan kebiasaan yang dimiliki oleh masyarakat di Desa Alu dalam mengelola hutan terdapat kegiatan yang dilarang dilakukan karena dapat merusak fungsi hutan yaitu sebagai sumber air yang dapat menyebabkan kelestarian lingkungan terganggu. Larangan-larangan tersebut yaitu larangan memanfaatkan lahan dan menebang kayu dalam kawasan pangngale piparakkeang. Larangan ini mengandung makna untuk mempertahankan kelestarian hutan dan sebagai sumber air untuk berbagai kebutuhan masyarakat. Apabila hutan tersebut terganggu dan berubah fungsinya maka kesejahteraan masyarakat juga akan terancam. Larangan tersebut juga mengandung makna untuk mencegah banjir dan tanah longsor. Selain itu, kerusakan hutan ini juga berarti merusak ekosistem yang ada di dalamnya sehingga hutan tersebut tidak dapat lagi tumbuh menjadi habitat bagi tumbuhtumbuhan dan hewan.

\section{Kearifan lokal dalam bentuk ajakan}

Kerarifan lokal masyarakat dalam bentuk ajakan dapat dilihat pada konsep menanam kayukayuan pada kebun mereka, ajakan untuk menanam 
sebelum menebang. Kearifan ini mengandung makna untuk melestarikan lingkungan, keberlanjutan fungsi hutan, dan mencegah bencana-bencana alam yang sering terjadi seperti banjir dan longsor. Konsep untuk membuat teras dan bedeng-bedengan merupakan usaha konservasi tanah yang dilakukan oleh masyarakat berdasarkan pengetahuan dan pemahaman yang mereka miliki, serta ritual bacabaca maccera' manurung dianalisis agar ada penekanan untuk menebang pohon.

\section{Perubahan Kearifan Lokal Masyarakat}

Awalnya masyarakat Desa Alu memiliki kearifan-kearifan terhadap lingkungan sekitar kebebasan pencurian hasil alam. Sedangkan Njurumana \& Gerson (2006) mengatakan bahwa banyak dijumpai kearifan lokal yang sudah tererosi dan memudar sehingga tidak lagi dipatuhi dan dihormati karena tingginya interaksi masyarakat lokal terutama kaum mudanya dengan budaya luar yang tanpa disadari memiliki peran terhadap melemahnya kearifan lokal. Hilangnya kearifan lokal berakibat pada hilangnya salah satu instrumen kepedulian memelihara sumber daya hutan, tanah dan air.

Pertambahan jumlah penduduk menyebabkan kebutuhan akan sumber daya hutan semakin meningkat. Pertambahan jumlah penduduk yang diikuti oleh peningkatan kebutuhan ekonomi membuat masyarakat menggunakan segala cara untuk memenuhi kebutuhan hidupnya termasuk memanfaatkan sumber daya hutan secara berlebihan. Penduduk Desa Alu mengalami peningkatan dari tahun ke tahun, pada tahun 2004 sebanyak 12.119 orang, tahun 200512.204 orang, tahun 200612.368 orang, tahun 200712.429 orang dan tahun 200812.492 orang.

Wilkinson (1973) dalam Dassir (2007) menyatakan bahwa pada umumnya masyarakat tradisional dalamkehidupannyamencobamelakukan pengelolaan sumber daya alam untuk mencapai keseimbangan ekologis. Pengelolaan yang biasa dilakukan antara lain dengan melalui pranata sosial budaya dan kepercayaan mereka. Keseimbangan ekologis itu akan rusak atau berubah apabila masyarakat tradisional mengadakan hubungan yang intensif dan bebas dengan dunia luar atau adanya misi (program atau kebijakan) dari luar yang datang pada lingkungan masyarakat tradisional. Akibatnya segala kepercayaan tradisional atau pantangan tradisional itu menjadi hilang. Untuk mengatasi kerusakan keseimbangan ekologis, masyarakat tradisional beradaptasi dengan mengembangkan teknologi baru untuk mendapatkan peningkatan produktivitas sumberdaya alam. Sedangkan keseimbangan hubungan ekologi akan ambruk apabila masyarakat tradisional telah dipengaruhi budaya luar atau masyarakat telah mengubah keseimbangan dan tatanan baru maka sistem teknologi baru akan berkembang.

\section{KESIMPULAN}

Aktivitas masyarakat Desa Alu pada kawasan hutan lindung di Desa Alu adalah melakukan pemanenan kayu-kayuan sebagai bahan pembuat dan perbaikan rumah serta kayu bakar, pemanenan rotan, bambu, aren, lebah madu dan hasil hutan lainnya. Kearifan lokal masyarakat Desa Alu dalam memanfaatkan sumberdaya hutan di kawasan hutan lindung sudah mengalami pengikisan nilai. Oleh karena itu, perlu dilakukan upaya pemberdayaan nilai kearifan lokal oleh pihak-pihak terkait dalam kegiatan pemanfaatan kawasan hutan lindung serta memotivasi masyarakat untuk tetap menjaga kelestarian dan keberlangsungan hutan dan eksistensi dari setiap hasil hutan yang dimanfaatkan.

\section{DAFTAR PUSTAKA}

Dassir, M. 2007. Dinamika Usaha Wanatani dan Sistem Tenur pada Sub DAS Minlareng Hulu di Kabupaten Maros Provinsi Sulawesi Selatan, Disertasi tidak diterbitkan. Program Pasca Sarjana Universitas Hasanuddin, Makassar.

Iskandar. 1992. Teknologi Perdagangan di Indonesia Studi Kasus dari Daerah Badui Selatan Jawa Barat. Djambatan. Jakarta.

Njurumana dan N. D. Gerson. 2006. Nilai Penting Kearifan Lokal dalam Rehabilitasi Lahan. http://www.dephut.go.id/ INFORMASI/MKI/06VI/06INilai\%20penting.htm. [diakses tanggal 1 Agustus 2010].

Nurhayati. 2005. Kearifan Tradisional Masyarakat Adat dalam Pengelolaan Hutan Adat Rumbio di Kabupaten Kampar Provinsi Riau. Jurnal Info Sosial Ekonomi. Pusat Penelitian dan Pengembangan Sosial Budaya dan Ekonomi Kehutanan. Vol. 5 (1) : 81-89. 